\title{
Seroprevalence of Dengue Virus IgG among Children 1 - 15 Years, Selected from an Urban Population in Karachi, Pakistan: Population Based Study
}

\author{
Shakeel Ahmed1,2*, Syed Rehan Ali1, Farhana Tabassum ${ }^{1}$ \\ ${ }^{1}$ Department of Paediatrics and Child Health, Aga Khan University Hospital, Karachi, Pakistan \\ ${ }^{2}$ Department of Paediatrics, Bahria University Medical and Dental College, Karachi, Pakistan \\ Email: ${ }^{*}$ shakeel.ahmed@aku.edu
}

Received 2 February 2015; accepted 17 May 2015; published 21 May 2015

Copyright (C) 2015 by authors and Scientific Research Publishing Inc.

This work is licensed under the Creative Commons Attribution International License (CC BY). http://creativecommons.org/licenses/by/4.0/

(c) $\underset{\mathrm{EY}}{\mathrm{B}}$ Open Access

\section{Abstract}

Objectives: This was to estimate the proportion of Dengue virus specific IgG ELISA among asymptomatic children between the ages of 1 year to 15 years, residing in an urban population of Karachi. Design: Cross-sectional study. Settings: Subjects were selected from Garden, Karachi; an urban area located adjacent to the Central district of Karachi. Participants: Children of ages 1 year to 15 years, of either sex, residing in the urban area of Garden, Karachi for more than 1 year were selected for the study. Those with a history of yellow fever or using corticosteroids within 1 month of recruitment were excluded. Outcome measures: Data were collected on socioeconomic status of households, medical history, including previous dengue infection, general examination findings and anthropometric indices. Blood samples were collected and sent to Research Laboratories, AKU for determining complete blood counts and serum IgG antibodies for Dengue. All collected information was then analyzed for ascertaining the predicting factors for positive IgG among children less than 15 years. Results: From a total of 900 subjects, $46 \%$ were found to have positive IgG in their bloods. Our results revealed that a male child of age more than $\mathbf{1 0}$ years was more likely to be IgG positive. Other risk factors identified with the seropositivity included lower household income and absence of anemia, thrombocytopenia and lack of hand washing. Conclusions: The study indicated a significant proportion of children under 15-year-old infected with Dengue virus, with a potential risk of severe complications, if re-infected with dengue. Stringent measures are still needed by both public and private authorities to contain dengue outbreaks, and reducing the proportion of associated mortality, as seen in the previous years. Trial registration: Seed Money Grant (ID\# SM090101) was awarded to the corresponding author by Research Committee, Faculty of Health Sciences, Aga Khan University, Pakistan.

\footnotetext{
${ }^{*}$ Corresponding author.
}

How to cite this paper: Ahmed, S., Ali, S.R. and Tabassum, F. (2015) Seroprevalence of Dengue Virus IgG among Children 1 15 Years, Selected from an Urban Population in Karachi, Pakistan: Population Based Study. Open Journal of Pediatrics, 5, 128-133. http://dx.doi.org/10.4236/ojped.2015.52019 


\section{Keywords}

\section{Dengue Virus, IgG, Cross-Sectional, Thrombocytopenia, Hand-Washing, Anemia}

\section{Introduction}

With an estimated 50 million infections per year across many countries, Dengue is now recognized as one of the major public health problems worldwide [1]. It is a mosquito-borne illness belonging to the genus flavivirus and consisting of 4 distinct serotypes, namely DENV-1, DENV-2, DENV-3 and DENV-4 [2]. In majority of the cases, the illness is self-limiting with mild symptoms such as fever, rash and joint pain (Dengue Fever). However, this may predispose to a severe form (dengue hemorrhagic fever) with infection with a different serotype [3] [4].

Today, dengue is endemic in more than 100 countries across Asia, Africa, America, Eastern Mediterranean, and West Pacific. Central to this is the enlarging habitat of its vectors, Aedes aegypti and Aedes albopictus. Aedes aegypti in particular, is highly adaptive in crowded areas; hence epidemics have been seen in cities with un-planned urbanization and overcrowding [5] [6].

Pakistan also had its share of dengue outbreaks in the recent years owing to the factors mentioned above. Epidemics have been reported especially in urban areas of Karachi and Lahore; situation worsening especially after monsoonal rains and floods. In October 2010, a total of 1809 cases were suspected out which 881 cases were confirmed of Dengue infection [7]. In 2011, worst outbreak occurred in the country when more than 14,000 people were affected with dengue with over 300 deaths [8].

Considering the current situation of Dengue virus and unavailability of data in Pakistan urgent attention and oversight is required to ensure effective preventive and curative program development. The objective of this study was to estimate the proportion of Dengue virus specific IgG ELISA among asymptomatic children between the ages of 1 year to 15 years, residing in an urban population of Karachi. When re-infected this population would potentially be at a higher risk of developing severe forms of dengue hemorrhagic fever.

\section{Methodology}

\subsection{Study Design/Selection Criteria}

A cross sectional survey was conducted from September 2011 to February 2012 to estimate the prevalence of dengue virus. The study cohort consisted of children between one to 15 years of age. The study participants were stratified by geographical zone and age group. There were four zones (East, West, North and South) in the Garden area. The participants were divided into three age groups of 1 - 5 years, 6 - 10 years and 11 - 15 years. Seventy five children were included from each age group in each zone to ensure that the sample was representative not only 1 zone that why each zone was divided equally. Thus a total of 900 children were enrolled in the study and for the selection of respondents systematic random sampling technique was used.

\subsection{Selection of Households}

After the distribution of zones and ages the second stage was selection of the household's. To select the 1st household Right Hand Rule was followed. Selection of households was done through Systematic Random technique within the starting point of zone. Interview was conducted from every 10th house hold where having at least one child under the age of 1 - 15 years and where the child's family gave informed written consent, before consent full explanation of the study was provided.

\subsection{Selection of Respondents}

As mentioned earlier, every 10th household was selected for the interview .If there were two or more family with having eligible targeted children in one selected $\mathrm{HH}$ only 1 child was selected.

House hold selection was made by using the Health Facility Utilization Survey 2010 conducted by Department of Paediatrics \& Child Health, Aga Khan University Karachi. 


\subsection{Data Collection}

After taking written consent from the parents/guardians, data was collected by research medical officers using a questionnaire, specially prepared for this survey. Information was collected on household socioeconomic status, medical history of febrile episodes including previous dengue infection followed by general clinical examination. Anthropometry height (in cms) and weight (in kilograms) was also performed. Blood samples were collected from the subjects and sent to Research Laboratory, Aga Khan University, Pakistan for determining complete blood counts and serum IgG antibodies for Dengue. Complete blood counts were tested using automated hematology analyzer (Beckman).Dengue IgG antibodies was determined by Enzyme Linked ImmunoSorbent Assay (ELISA), using Pan Bio Kits (Dia. Pro Diagnostic BioprobesSrl—Via Columella, 31 Milan—Italy).

\subsection{Sample Size}

The sample size was calculated using point estimation. We assumed that if $5 \%$ of the population has been infected with dengue virus, the minimum estimated number to recruit was 852 subjects, at $5 \%$ level of significance and precision of 0.02 .

\subsection{Statistical Analysis}

Data was analyzed using IBM SPSS (Statistical Package for Social Sciences) for Windows version 19 (IBM ${ }^{\circledR}$ SPSS $^{\circledR}$ Statistics, IBM Corporation, Somers, NY, USA). Frequencies were expressed in Means ( \pm standard deviations) calculated for quantitative variables, while proportions were assessed for categorical variables. Factors predicting likelihood to positive IgG among subjects was assessed by multiple logistic regressions. p-value if less than 0.05 was considered significant.

\subsection{Ethical Approval}

The study was approved by the Ethics Review Committee of the Aga Khan University, Pakistan.

\section{Results}

Table 1 shows the different characteristics of the population by IgG positivity. A total of 900 subjects, comprising of 461 males and 439 females, were surveyed, from which 419 (46\%) had IgG antibodies in their blood. The mean age for IgG positive subjects was relatively higher to the IgG negative subjects $(9.5 \pm 3.7$ years vs. $6.7 \pm$ 4.2 years; p-value < 0.001). About $61 \%$ children, with positive IgG were of the age of more than 10 years (Figure 1).

Household characteristics revealed that likelihood for previous dengue infection is more when hand washing is not practiced and no water purifying measures are taken. Likelihood for previous dengue infection is more if the average monthly income is less than Rupees 8000 (Table 1).

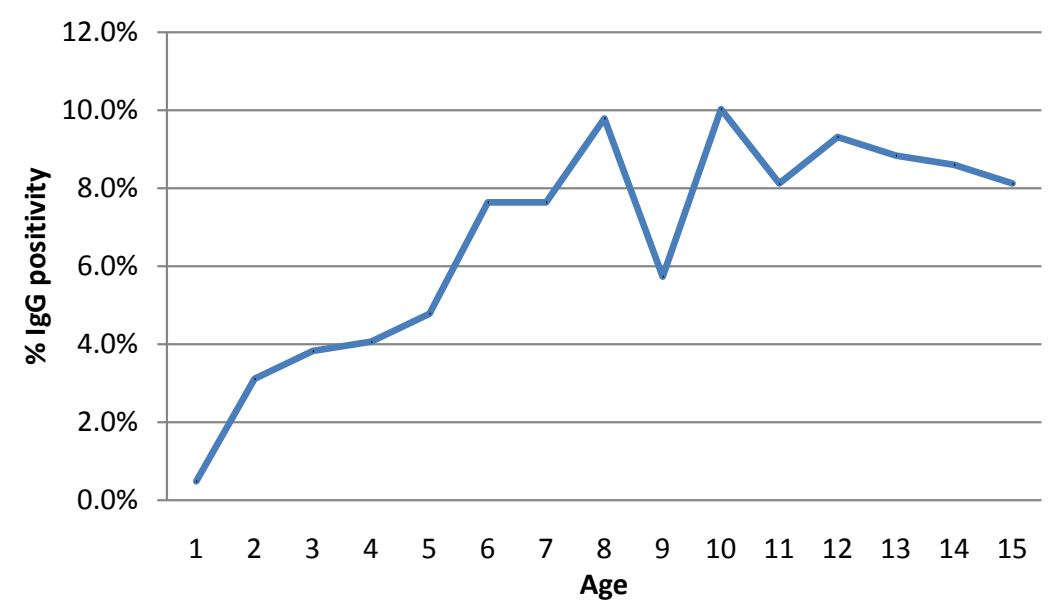

Figure 1. Trends of IgG positivity across age groups of subjects. 
Table 1. Characteristics of the population with respect to positive IgG $(\mathrm{n}=900)$.

\begin{tabular}{|c|c|c|c|c|c|c|c|}
\hline \multicolumn{2}{|c|}{ Characteristics } & \multirow{2}{*}{\begin{tabular}{|c|} 
Total \\
391
\end{tabular}} & \multirow{2}{*}{$\begin{array}{c}\text { IgG + ve }{ }^{\mathbf{1}} \\
122(31)\end{array}$} & \multirow[t]{2}{*}{ Wald $X^{2}$} & \multirow[t]{2}{*}{ df } & \multirow[t]{2}{*}{ p-value } & \multirow{2}{*}{$\begin{array}{c}\text { OR }(\mathbf{9 5} \% \mathbf{C I}) \\
1\end{array}$} \\
\hline Age groups & 1 - 5 years & & & & & & \\
\hline & 6 - 10 years & 258 & $143(55)$ & 1.84 & 1 & $<0.001$ & $2.74(1.98-3.80)$ \\
\hline & More than 11 years & 251 & $154(61)$ & 54.7 & 1 & $<0.001$ & $3.50(2.51-4.88)$ \\
\hline \multirow[t]{2}{*}{ Sex } & Female & 439 & $192(44)$ & & & & 1 \\
\hline & Male & 46 & 227 (49) & 2.74 & 1 & 0.09 & $1.25(0.96-1.62)$ \\
\hline \multirow[t]{2}{*}{ Water purification } & Yes & 235 & 91 (39) & & & & 1 \\
\hline & No & 665 & $328(49)$ & 7.79 & 1 & 0.01 & $1.54(1.14-2.09)$ \\
\hline \multirow[t]{2}{*}{ Hand washing } & Yes & 497 & $212(43)$ & & & & 1 \\
\hline & No & 403 & $207(51)$ & 6.77 & 1 & 0.01 & $1.42(1.09-1.85)$ \\
\hline \multirow[t]{4}{*}{ Average monthly income } & More than Rs 15,000 & 168 & 65 (39) & & & & 1 \\
\hline & Rs 10,001 - 15,000 & 179 & $86(48)$ & 3.08 & 1 & 0.08 & $1.46(0.96-2.25)$ \\
\hline & Rs 8000 - 10,000 & 315 & $136(43)$ & 0.91 & 1 & 0.34 & $1.20(0.82-1.76)$ \\
\hline & Less than Rs 8000 & 238 & $132(55)$ & 10.97 & 1 & 0.001 & $1.97(1.32-2.95)$ \\
\hline \multirow[t]{2}{*}{ Anemia } & Present & 142 & $36(25)$ & & & & 1 \\
\hline & Absent & 758 & $383(50)$ & 28.7 & 1 & $<0.001$ & $3.02(2.01-4.52)$ \\
\hline \multirow[t]{2}{*}{ Thrombocytopenia } & Present & 18 & $3(17)$ & & & & 1 \\
\hline & Absent & 882 & $416(47)$ & 5.6 & 1 & 0.02 & $4.50(1.29-15.66)$ \\
\hline \multirow[t]{2}{*}{ Hepatosplenomegaly } & Absent & 770 & $354(46)$ & & & & 1 \\
\hline & Present & 130 & $65(50)$ & 0.72 & 1 & 0.4 & $1.20(0.80-1.70)$ \\
\hline
\end{tabular}

${ }^{1}$ Expressed as n (\%).

Table 2 summarizes the adjusted logistic regression model signifying preponderance patterns for IgG positive subjects. Male children of increasing age were more likely to be IgG positive. The data also shows that children with anemia or thrombocytopenia were less likely to have had a previous dengue infection. The adjusted model revealed that households with lower average income and no water purifying method employed resulted in greater preponderance of previous dengue infection among the target population.

\section{Discussion}

Our study indicated that $46 \%$ of the population had been infected with dengue virus, making them susceptible to severe forms of dengue fever. To date, no study of this sort had been conducted from Karachi, Pakistan.

Our study showed that Dengue IgG was found more in elderly children (more than 5 years). This finding has also been reported by other researchers in their settings [9]-[11]. Our study also showed greater preponderance of dengue IgG antibodies in males compared to females. Where reports suggest no significant differences associated with sex that might be different from Pakistan's perspective owing to the fact that majority of the females remain indoors while males spend their maximum time outside [11]-[13]. As mentioned previously, the dengue vectors are highly adaptable to any environment, hence it is probable for male children of such ages to become exposed to its habitat more often and contracting the virus.

In our study, analysis revealed dengue IgG positivity to be more among lowest categories of socioeconomic position, comprising of $19 \%$ of the studied population. This was consistent with the study reported from Brazil [13] [14]. In our study, the finding was perhaps expected as Garden is a modern urban area with high rise buildings and inhabited by affluent communities. 
Table 2. Adjusted odds ratios (with 95\% CI) computed using multiple logistic regression.

\begin{tabular}{|c|c|c|c|c|c|}
\hline \multicolumn{2}{|c|}{ Characteristics } & \multirow[t]{2}{*}{ Wald $X^{2}$} & \multirow[t]{2}{*}{ df } & \multirow[t]{2}{*}{ p-value } & \multirow{2}{*}{$\begin{array}{c}\text { OR }(\mathbf{9 5} \% \mathbf{C I}) \\
1\end{array}$} \\
\hline Age groups & 1 - 5 years & & & & \\
\hline & 6 - 10 years & 24.9 & 1 & $<0.001$ & $2.40(1.70-3.38)$ \\
\hline & More than 10 years & 44.4 & 1 & $<0.001$ & $3.34(2.34-4.76)$ \\
\hline \multirow[t]{2}{*}{ Sex } & Female & & & & 1 \\
\hline & Male & 4.34 & 1 & 0.04 & $1.35(1.02-1.80)$ \\
\hline \multirow[t]{2}{*}{ Water purification } & Yes & & & & 1 \\
\hline & No & 4.5 & 1 & 0.03 & $1.43(1.02-2.00)$ \\
\hline \multirow[t]{4}{*}{ Average monthly income } & More than Rs 15,000 & & & & 1 \\
\hline & Rs 10,001-15,000 & 4.54 & 1 & 0.03 & $1.65(1.04-2.61)$ \\
\hline & Rs 8000-10,000 & 1.35 & 1 & 0.25 & $1.28(0.85-1.93)$ \\
\hline & Less than Rs 8000 & 13.1 & 1 & $<0.001$ & $2.26(1.45-3.51)$ \\
\hline \multirow[t]{2}{*}{ Anemia } & Present & & & & 1 \\
\hline & Absent & 14.7 & 1 & $<0.001$ & $2.32(1.51-3.57)$ \\
\hline \multirow[t]{2}{*}{ Thrombocytopenia } & Present & & & & 1 \\
\hline & Absent & 4.54 & 1 & 0.03 & $4.07(1.12-14.8)$ \\
\hline
\end{tabular}

Employing strategies for water purification was also found to be important in the study, indicating a more likelihood to prior dengue infection in absence of water purification. In our analyses, 39\% reported to purify water for consumption, using methods such boiling (15\%), filtering (0.02\%) and chlorination (0.001\%). It can be conceived that untreated water would be the possible niche for the Aedes mosquitoes to breed and multiply.

Unique in this study is the positive association of stunting with $\operatorname{IgG}$ positivity $\left(\mathrm{X}^{2}=4.12, \mathrm{df}=1, \mathrm{p}\right.$-value $=$ 0.042). Our analysis also revealed a lesser likelihood of IgG positivity in presence of anemia and thrombocytopenia. These 3 conditions are pretty prevalent in this part of the world, each clinical correlate limiting us to offer any interpretation to its significance with IgG positivity.

Some limitations are to note in this study. For instance we opted to collect information from a relatively affluent community of Karachi. Though previous studies on Dengue from around the world have indicated Dengue to be a threat for the urban areas, including squatter settlements would have provided a comparative picture showing proportional associations of positive IgG with overcrowding, sanitation and presence of domestic animals [6] [7]. The important and interesting aspect is to assess the serotype of the most prevalent dengue virus in these settings, as limited literature suggests DENV-2 and DENV-3 to be most prevailing in Pakistan [7].

\section{Conclusion}

The study indicates a significant part of the population of children less than 15 years in Garden, Karachi is infected with Dengue virus. Though severe dengue infections occur in a comparatively smaller population, but the children identified in this study are definitely at risk of severe complications in case of re-infection [6]. New cases are reported with the advent of monsoons and monsoonal rains. Pakistan has received its share of monsoon rains and potentially at risk for another dengue outbreak. Despite public and private measures for containing the infection, we are far away from reducing the rates of dengue in our population. Serious measures are needed to control the mosquito vector populations and reduce the associated morbidity and mortality, as seen in the previous years.

\section{Acknowledgements}

The study was carried out using the Aga Khan University Seed Money Grant awarded to SA. 


\section{Competing Interests}

The authors declare no competing interests.

\section{Authors' Contributions}

SA, SRA and FT were involved in data collection, entry, analysis, revision and manuscript writing.

SA was involved in study conception, manuscript writing, data collection, entry, analysis editing and overall supervision.

All authors have read and approved the final manuscript.

\section{Data Sharing Statement}

There is no additional data available.

\section{References}

[1] World Health Organization (2009) Dengue: Guidelines for Treatment, Prevention, and Control. World Health Organization, Geneva.

[2] Sharma, Y., et al. (2012) Seroprevalence and Trend of Dengue Cases Admitted to a Government Hospital, Delhi5-Year Study (2006-2010): A Look into the Age Shift. International Journal of Preventive Medicine, 3, 537-543.

[3] World Health Organization (1997) General Considerations. Dengue Hemorrhagic Fever: Diagnosis, Treatment, Prevention and Control. World Health Organization.

[4] Idrees, S. and Ashfaq, U.A. (2012) A Brief Review on Dengue Molecular Virology, Diagnosis, Treatment and Prevalence in Pakistan. Genetic Vaccines and Therapy, 10, 6. http://dx.doi.org/10.1186/1479-0556-10-6

[5] Black, W.C.T., et al. (2002) Flavivirus Susceptibility in Aedes aegypti. Archives of Medical Research, 33, $379-388$. http://dx.doi.org/10.1016/S0188-4409(02)00373-9

[6] Simmons, C.P., et al. (2012) Dengue. New England Journal of Medicine, 366, 1423-1432. http://dx.doi.org/10.1056/NEJMra1110265

[7] Jahan, F. (2011) Dengue Fever (DF) in Pakistan. Asia Pacific Family Medicine, 10, 1. http://dx.doi.org/10.1186/1447-056X-10-1

[8] Rai, M.A. (2011) Epidemic: Control of Dengue Fever in Pakistan. Nature, 479, 41. http://dx.doi.org/10.1038/479041d

[9] Gupta, P., et al. Assessment of World Health Organization Definition of Dengue Hemorrhagic Fever in North India. Journal of Infection in Developing Countries, 4, 150-155. http://dx.doi.org/10.3855/jidc.708

[10] Thai, K.T., et al. (2005) Seroprevalence of Dengue Antibodies, Annual Incidence and Risk Factors among Children in Southern Vietnam. Tropical Medicine International Health, 10, 379-386. http://dx.doi.org/10.1111/j.1365-3156.2005.01388.x

[11] Yamashiro, T., et al. (2004) Seroprevalence of IgG Specific for Dengue Virus among Adults and Children in Santo Domingo, Dominican Republic. American Journal of Tropical Medicine and Hygiene, 71, 138-143.

[12] World Health Organization (2011) Taking Sex and Gender into Account in Emerging Infectious Disease Programmes: An Analytical Framework. World Health Organization, Geneva.

[13] Siqueira, J.B., et al. (2004) Household Survey of Dengue Infection in Central Brazil: Spatial Point Pattern Analysis and Risk Factors Assessment. American Journal of Tropical Medicine and Hygiene, 71, 646-651.

[14] Teixeira, M.G., et al. (2012) Risk Factors for the Incidence of Dengue Virus Infection in Preschool Children. Tropical Medicine \& International Health, 17, 1391-1395. http://dx.doi.org/10.1111/j.1365-3156.2012.03086.x 